\title{
Meninas! Sejam educadas por Barbie e "com" a Barbie...1
}

\section{Girls! Be educated by Barbie and "with" Barbie...}

\author{
Fernanda Theodoro Roveri ${ }^{2}$ \\ Carmen Lúcia Soares ${ }^{3}$
}

\begin{abstract}
RESUMO
Desde que nascem, as crianças vivenciam certas experiências sociais que são determinadas pelo fato de serem meninos ou meninas. Que concepções de gênero, corpo e infância são apresentadas por uma boneca que quer ser a melhor amiga da criança-menina? Este artigo analisa o sucesso da boneca Barbie, os modos de educar meninas e os mecanismos publicitários que configuram sua personalidade versátil e produzem certos modos de pensar, agir e relacionar-se com o mundo.
\end{abstract}

Palavras-chave: Barbie; corpo; infância; gênero; educação.

\begin{abstract}
Ever since children are born, they live certain social experiences that are determined by the fact of being boys or girls. What conceptions of gender, body and childhood are presented by a doll that wants to be the best friend
\end{abstract}

${ }^{1} \mathrm{O}$ conteúdo deste artigo é mais amplamente desenvolvido na dissertação de mestrado de ROVERI, Fernanda Theodoro. Barbie: tudo o que você quer ser - Ou considerações sobre a educação de meninas. Universidade Estadual de Campinas (UNICAMP), Faculdade de Educação, 13/08/08, 105 p. Orientadora: Profa. Dra. Carmen Lúcia Soares. A pesquisa foi iniciada em 2004 no Trabalho de Conclusão de Curso de Pedagogia.

${ }^{2}$ Doutoranda em Educação pela Unicamp, professora de Educação Infantil na rede Municipal de Campinas, Brasil.

${ }^{3}$ Livre-docente pela Universidade Estadual de Campinas - UNICAMP, onde leciona desde 1987. Doutorou-se em 1996, na mesma universidade, com uma tese sobre a história da educação do corpo. Também é pesquisadora do CNPq e atua no Programa de Pós-Graduação em Educação da Unicamp. 
of the child-girl? This article analyzes the success of the Barbie doll, the ways to educate girls and the advertising mechanisms that configure its versatile personality and produce certain ways of thinking, acting and relating with the world.

Keywords: Barbie; body; childhood; gender; education.

\section{Meninas! Sejam educadas por Barbie e "com" a Barbie...}

Imortalidade, perfeição e juventude eterna: Barbie tem sua imagem modelada no museu de cera de Grévin, em Paris. Lá está a boneca posando em meio a outras estátuas que reproduzem seres humanos. Seres que têm sua aparência cristalizada num período da vida, a juventude; a cera determina a imagem eterna que deverá ficar em nossa memória e designa um cenário de celebridades e ícones admirados. A Barbie original é de plástico, mas a cera das estátuas em que está reproduzida cria um corpo semelhante ao humano e aproxima sua imagem a dos outros humanos lá expostos, fazendo-nos crer que fora dali ela também tem "vida real". Sua beleza eterna fica presa e imóvel na cera, no plástico. Mas qual é sua história, o que ela fez para estar ali, em meio a astros e estrelas?

Uma cintura com oito centímetros e meio, um quadril com dez centímetros, vestir a menor numeração de roupas e deixar a barriga definida à mostra! Treze centímetros de bumbum, imune a celulite, estria, culote ou gordura, a qualquer marca de degradação física... Pernas longas, depiladas e sem varizes que alcançam sete centímetros já contando o salto, pois o pé sempre deve ficar nas pontas. Seios rígidos que medem $12,5 \mathrm{~cm}$ e que possuem consistência plástica. Cabelos longos, lisos, louros "naturais" desde a raiz! Olhos azuis, face sem rugas, maquiagem definitiva. Juntando todos esses atributos e dispondo-os num frasco branco de $29 \mathrm{~cm}$, tem-se a medida exata para uma intocável silhueta cheia de curvas, um modelo de corpo feminino que se multiplica duas vezes a cada segundo e disponibiliza sua boa forma para 120 milhões de crianças do mundo todo, a cada ano.

Quando nasce uma menina, logo a embrulham em cor-de-rosa, selam-na e estampam-na com uma marca: Barbie. Sua mãe a enfeita com laços, fitas e apetrechos que evocam a imagem da deusa, fada loura e fiel companheira de todas as garotas. É preciso fazê-la crescer meiga, graciosa, delicada. Ensiná-la a ser menina, sensível e romântica. Logo que a pequena mocinha começa a andar e a falar, a família a acomoda à frente da televisão para aprender com os vários filmes - ou "manuais de boas maneiras" -, como, por exemplo, em Barbie - 
Quebra Nozes (2002), cujo conteúdo diz à menina que se ela for "generosa, inteligente e corajosa, tudo é possível..."; ou em Barbie Fairytopia (2004), em que se vê e lê: "Ela conhecerá novas pessoas que testarão sua coragem e aprenderá o valor da verdadeira amizade".

Em seguida, os pais permitem-lhe acessar o site mágico da boneca e participar de várias "atividades bonitas e educativas". A cada ano de aniversário, a menina transforma-se pouco a pouco em uma requintada bonequinha e ganha de presente algum amuleto Barbie para aumentar sua coleção. É assim até a adolescência, fase em que Barbie agora troca de pele e aparece com toda a sua popularidade de modelo fashion, que ensinará a garota a se portar como uma mulher sedutora, admirável e de sucesso, conferindo à própria menina a responsabilidade de manter imponente sua aparência. As revistas de beleza irão ajudar-lhe a transfigurar-se naquela em que desde a tenra idade lhe fora parâmetro de feminilidade, o mercado cosmético apresentará tudo o que se fizer necessário para manter sua visibilidade e a medicina estética, por sua vez, oferecerá "a possibilidade de buscar uma solução aos problemas que o envelhecimento acarreta à pessoa" (GÓMEZ, 2003, p. 95).

No Brasil, $80 \%$ das mulheres a partir dos 13 anos estão insatisfeitas com algo no seu corpo ${ }^{4}$ e metade delas considera-se acima do peso. Além disso, 93\% das mulheres afirmam que a mídia é capaz de gerar uma busca doentia por um padrão de beleza e $73 \%$ acreditam que a moda é feita para magras. Parece que a boneca Barbie e sua quase onipresença na vida de meninas é um elemento importante na configuração deste ideário que se expande e alimenta os mercados da beleza.

Ser conhecida, colecionada, admirada e elevada ao nível de personalidade imortal: a sociedade mercadológica tem injetado na boneca todo oxigênio de que ela precisa para continuar nova e viva no imaginário infantil. Completando meio século de aparição ao público, Barbie, ao contrário de muitos brinquedos, nunca foi esquecida e tampouco envelheceu nas prateleiras das lojas. Quando completou 30 anos, sua intensiva indústria já havia vendido 600 milhões de bonecas e mais de um bilhão de acessórios, dentre os quais 1,2 milhão de pares de sapato e 35 mil bolsas (O'SICKEY, 2002, p. 32).

Graças à descoberta da criança como consumidora em potencial, a partir dos anos de 1950, os publicitários passaram a falar diretamente com ela. A princípio, a venda de brinquedos era direcionada aos pais, mas os criadores de Barbie foram os pioneiros em desenvolver técnicas de marketing e comerciais

${ }^{4}$ Dados apontados na pesquisa Opiniões e hábitos da mulher do século 21, feita pelo Grupo Datastore nas cidades de São Paulo e Rio de Janeiro (MÉDOLA, 2007, p. 8). 
voltados ao público infantil ${ }^{5}$. As propagandas iniciais da boneca sempre foram testadas antes com um grupo de meninas. Se elas não gostassem, o comercial não era veiculado na televisão. As primeiras imagens televisivas de Barbie sugeriam que ela era uma modelo adolescente, pessoa real que até se mexia nas propagandas. Barbie nunca era mencionada como uma boneca comum. Há uma narrativa construída para transformá-la em personagem e marcar presença no imaginário da menina, fazendo-a acreditar que, por adquirir a boneca, uma melhor amiga e companheira lhe será confiada. A letra da música veiculada na primeira propaganda, no final dos anos de 1950, é bastante elucidativa:

Barbie você é linda/ Barbie você me faz sentir/ Minha boneca Barbie realmente é real./ Barbie sorrindo tão pequena/ Sua roupa de dança toca um sino/ Na festa, ela lançará um feitiço/ Muitas bolsas, chapéus e luvas/ E todos os acessórios enfeitam a boneca/ Algum dia eu serei exatamente como você/ Até lá, eu sei bem o que farei/ Barbie, linda Barbie, eu vou acreditar que sou vocề .

É comum algumas crianças acharem que a Barbie realmente existe em pessoa. Afinal, seus fã-clubes, seu site e suas publicações fazem de conta que Barbie está interagindo com suas admiradoras, como uma espécie rara de amiga sábia e confidente. O logotipo da boneca costuma ser exposto em diversos eventos exclusivos para meninas frequentadoras de shoppings centers e um estúdio da boneca foi projetado para que as meninas recebessem o batismo, confirmando-se, assim, em seguidoras do estilo de vida Barbie. Neste ambiente, acomodadas em poltronas pink e observadas pelas bonecas nas vitrines, as meninas podiam escolher roupas, chapéus, plumas, bolsas e óculos, incorporando o visual sedutor de Barbie. Mas os meninos tinham que se dirigir a um outro lado, pois para eles fora reservado "um espaço irado, com paredes grafitadas. [...] Um ambiente radical, com bicicleta, pneus, skates, pistas, carrinhos, além de minimotos, para [...] levar suas máquinas e posar para fotos dentro da Garagem Hot Wheels"7.

A publicidade não vende apenas a boneca, produto de plástico, ela trabalha para expandir o brinquedo no nível de uma marca, pois assim qualquer coisa

${ }^{5}$ Em 1955 os criadores da boneca investiram meio milhão de dólares para veicular, por 52 semanas, propagandas de brinquedos no programa Clube do Mickey Mouse, provando que era possível atingir altas vendas com o anúncio direto à criança. Ver Lord (2004, p. 20).

${ }^{6}$ Tradução livre feita a partir do comercial. Disponível em: <http://www.youtube.com/ watch? $\mathrm{v}=\mathrm{h} 8$-avPUxyno $>$.

${ }^{7}$ Correio Criança - "Eventos", Campinas, Correio Popular, p. E8, 16 jun. 2007. 
pode ser da Barbie: roupas, artigos escolares, esportivos, eletrônicos, entre outros. Klein (2006, p. 33), ao analisar o expansionismo cultural das marcas, faz uma crítica ao crescente desejo dos fabricantes em transformar um logo em estrela e produzir ambientes reais de grife, tal como aconteceu em 1997 com uma rua, em Salford, na Inglaterra, que fora pintada inteiramente de rosa (casas, árvores, cães, carros...) para as comemorações do "mês de Barbie". A marca representa um modo de vida, um conjunto de atitudes, um conceito de feminilidade. Distanciada do produto, a marca Barbie pode ser o que quiser e estar em qualquer lugar, suas mãozinhas podem tocar ambientes reais e transformá-los em gigantescos logotipos cor-de-rosa, como, por exemplo, em 2007, quando uma "Casa Barbie" de tamanho real foi criada em Paris às margens do rio Sena, como parte da exposição "La Ville de Mademoiselle B."”.

Nem todas as crianças podem comprar os produtos que a publicidade da boneca se esforça para vender, mas qualquer pessoa consome os signos de gênero e sexualidade apresentados pela marca Barbie, que, vertiginosamente, produz certas formas de pensar, de agir, de estar e de se relacionar com o mundo.

[...] Sujeitos consomem não só mercadorias como também valores que estabelecem como deve ser o corpo, como devemos nos vestir, quais comportamentos valorizar, isso tudo não somente através das marcas de gênero, como também de raça/etnia, classe, geração, para citar algumas (SABAT, 2003, p. 153).

Desde que nascem, as crianças vivenciam certas experiências sociais que são determinadas pelo fato de serem meninos ou meninas. Os brinquedos vêm imbuídos de normas que definem o que é permitido e o que não é permitido para cada sexo, há um abismo que separa os "brinquedos fortes" destinados aos garotos, dos outros "brinquedos sensíveis" exclusivos das meninas ${ }^{9}$. Felipe e Guizzo (2003, p. 127) apontam que as propagandas de bonecas investem na ideia de que a vaidade supérflua e o consumo desenfreado são características inerentes ao feminino.

A palavra boneca é empregada em brinquedos feitos para meninas e os fabricantes preferem não usar a palavra "boneco" para denominar os perso-

8 "Barbie, quem diria, vai morar em Paris", O Globo on-line, 27 set. 2007. Disponível em: $<$ http://oglobo.globo.com/viagem/mat/2007/09/27/297922803.asp>. Acesso em: 28/9/2007.

${ }^{9}$ Mas vale ressaltar que essas dicotomias são criadas pelos adultos e que nem sempre têm o mesmo significado para as crianças no momento da brincadeira. 
nagens masculinos. O termo figuras de ação define os personagens velozes, maldosos, heróis e viris vendidos aos meninos. A publicidade de "brinquedos feitos para os meninos" traz outra definição de como eles devem comportar-se: as cores escolhidas para estampar a embalagem geralmente são mais escuras, os rostos ofensivos dos bonecos demonstram poder, seus membros são totalmente articulados para realizar inúmeros movimentos que simulam ação e coragem, juntamente com mensagens que demarcam a quem o brinquedo é dirigido, como esta do boneco Max Steel, caracterizado pela fabricante como "um super-herói inteligente e forte na medida certa, modelo exemplar para crianças, um herói que luta incessantemente contra o mal. Combinação única de fantasia e realidade". A proposta da brincadeira é destruir barreiras, atirar lanças e projéteis, emitir sons aterrorizantes, detonar vilões, "ser forte na medida certa e deixar o mundo mais seguro", como anuncia a fabricante do boneco (Mattel). A brincadeira com carrinhos também recebeu o discurso da "performance, atitude e velocidade". Trata-se de potencializar atitudes que encarnem a destruição, a "diversão destruidora" conforme afirma o fabricante ${ }^{10}$.

Essa é a lógica que preside o mundo dos brinquedos dos meninos. Seria a mesma para as meninas? Parece que não, pois as bonecas em sua maioria encarnam estereótipos de feminilidade como, por exemplo, a boneca Polly ${ }^{11}$, cuja coleção é composta por delicados jipes conversíveis, carrinhos com glitter, com essência de frutas, entre outros, e cor rosa, em sua maioria. Os platinados e cheirosos carrinhos das pequenas bonecas Polly carregam elementos para que não saiam do domínio "feminino". A publicidade oferece a narrativa que mantém o carrinho dentro das esferas socialmente aceitas para a brincadeira de uma menina: moda e diversão e não velocidade e destruição, como prometem os carrinhos para meninos.

\section{Moda, música e diversão: a educação de meninas, ou, o sedutor mundo virtual de Barbie...}

A promessa de favorecer o aprendizado e o desenvolvimento infantil não só é anunciada pelos fabricantes de brinquedos como também pela informática:

\footnotetext{
${ }^{10}$ Transcrição da propaganda do brinquedo Crashers Campo de Batalha, encontrada no "Guia de Merchandising para lojas 2008", da fabricante de brinquedos Mattel.

${ }^{11}$ Trata-se de uma boneca de $9 \mathrm{~cm}$ feita em material siliconizado pela Mattel, a mesma fabricante de Barbie.
} 
uma variedade de programas de computador é apropriada cada vez mais por escolas e espaços de entretenimento que disputam a atenção da criança. Quais são as formas de acessibilidade à informática apresentadas para meninos e meninas? Como as meninas são educadas pelos chamados "softwares educativos" e inúmeros jogos on-line? Qual compreensão do universo digital é reservada às crianças?

De acordo com Schwartz et al. (2006), se mulheres ainda não têm boa representatividade em laboratórios computacionais e têm menos aulas de programação computacional em escolas e universidades, é porque ainda prevalece o mito de que a mulher não tem competência tecnológica. Mas o afastamento das mulheres nessa área tem muito mais a ver com a forma com que a menina desde cedo é apresentada ao universo da informática e com a falta de divulgação do trabalho de mulheres cientistas, pois "assim como em outras áreas da ciência, as mulheres na informática permaneceram invisíveis e sua contribuição desconhecida" $"$.

Schiebinger (2001) mostra-nos que o ensino da matemática nos Estados Unidos é diferente para meninos e meninas, mencionando que muitas escolas utilizam, para ensinar matemática, ortografia e linguagem, um software educacional chamado Demolition Division, pelo qual a divisão é aprendida numa situação de guerra. Meninas geralmente acham chato o jogo de explosão e por isso as companhias responderam com um programa produzido só para elas: Barbie Super Model, beauty and the beast! De acordo com a autora, "meninos e meninas exibem interesses e habilidades semelhantes em matemática até cerca do sétimo e oitavo ano, quando muitas meninas começam a perder confiança em suas aptidões matemáticas e escolhem menos aulas de matemática" (SCHIEBINGER, 2001, p. 122).

É notável a existência de um mercado agressivo de jogos feitos por homens e para homens, como também é notável a existência de jogos feitos por mulheres para meninas que vão na direção oposta e ao encontro dos estereótipos. O CD-ROM Barbie Fashion Designer, produzido por Nancie Martin, executiva da Mattel, Brenda Laurel, Heather Kelley e Theresa Duncan, é exemplar. Para as editoras do jogo, as garotas são atraídas pelas cores rosa e lavanda, sprays de

${ }^{12}$ Schwartz et al. (2006, p. 20). Nesse artigo, as autoras apresentam exemplos de mulheres pioneiras que tiveram importante participação no desenvolvimento da computação, muitas delas formadas em matemática e ciências. Lembram ainda que quando os primeiros computadores começaram a ser utilizados, parecia óbvio que essa seria uma área feminina, uma vez que as mulheres tradicionalmente realizavam a atividade de "computar", resolvendo cálculos para os cientistas. Assim, seria esperado que elas continuassem a realizar essa atividade contando com a ajuda dos computadores (p. 12). 
cabelo, pintura das unhas e esses gostos podem ser convertidos em tecnologia. Nessa compreensão, o "domínio feminino" da informática dá-se nos limites de uma "programação rosa". O jogo vendeu meio milhão de cópias em seus dois primeiros meses de lançamento e é o software infantil mais comprado de todos os tempos.

As garotas devem ter seu próprio quarto pintado de rosa e preenchido com "parafernália de menina": essa é a ideia principal que define a elaboração de um jogo virtual para garotas interagirem com as "amigas Barbies". O jogo BarbieGirls, "um mundo virtual com muita moda, música e diversão"13.

Nele a menina recebe diversos protótipos de Barbie e escolhe aquele que melhor lhe representa nessa comunidade de dóceis garotinhas. Em seguida recebe um quarto que, durante o jogo, será decorado com os móveis e acessórios vendidos nas lojas virtuais. Esse espaço será visitado por outras meninas comportadas que estiverem conectadas ao jogo, elas poderão entrar nos quartos das demais usuárias para espiar a decoração, sentar no sofá de acordo com os cânones femininos estereotipados, ou seja, com as pernas fechadas e os braços encolhidos junto ao corpo e simular um "bate-papo" com a amiga: uma a uma, elas selecionam quaisquer frases prontas que os elaboradores do site pensaram ser as mais adequadas para uma conversa entre meninas:

Adorei sua roupa!/ Arrasou no look!/ Que fofo!/ Eu queria ter.../ Eu gosto de ser uma boa amiga/ Vamos fazer compras?/ Quer sentar?/ Que quarto lindo!/ Quanto estilo!/ Estou mega feliz agora!/ O meu irmão tem chulé!/ Eu queria ter asas de borboleta!/ Eu quero ir de pijama para a escola!/ Tem alguma coisa mais light para comer?/Alguém quer chocolate?/ Você precisa ter uma BarbieGirl/ Eu fiz um problema de matemática todo errado/ Eu parecia uma lesma na aula de ginástica!

Quando enjoarem da conversa, as meninas podem sair do quarto e passear na cidade para gastarem seu dinheiro. Podem visitar as lojas de roupas e acessórios, cinema, café, lojas de móveis para o quarto, pet shop, salão de beleza e o parque. Quando o dinheiro acabar, a garota pode receber mais se brincar de pintar as unhas de Barbie e suas amigas; se criar um videoclipe musical ou se arrumar o Ken para um encontro com a namorada Barbie... Mas a menina pode receber uma quantidade ainda maior de dinheiro se entrar no cinema e assistir aos trailers dos filmes de Barbie recém-lançados no mercado. Com o pagamento

${ }^{13}$ Disponível em: <www.barbiegirls.com.br>. Acesso em 3/3/2008. 
recebido, a menina passa o maior tempo fazendo compras para mudar seu visual ou o do seu quarto, ostentando-os para as outras usuárias conectadas ao sistema.

Inúmeros sites como esse são elaborados de acordo com perspectivas limitadas do que a menina precisa saber, ter e fazer para tornar-se mulher. Tomadas de decisões, histórias múltiplas, raciocínio lógico, interação com diferentes tipos de jogadores não estão disponíveis no "mundo com muita moda, música e diversão". O único personagem masculino que ilustra o BarbieGirls - além do namorado "Ken" num jogo em que a menina precisa vesti-lo para conquistar a Barbie - é um menino programado para passar pelo parque de skate na frente das garotas, que, ao vê-lo, podem selecionar a frase: "Olha aquele garoto!". Nos demais espaços, lojas, cinemas, quartos, não há a presença de quaisquer personagens diferentes das BarbieGirls. Dessa forma, o controlado ambiente não só modela a maneira de as usuárias conceberem umas às outras como também promete segurança, afastando delas o "perigo" do contato com meninas malcriadas e figuras do sexo masculino.

As muitas formas de fazer-se mulher ou homem, as várias possibilidades de viver prazeres e desejos corporais são sempre sugeridas, anunciadas, promovidas socialmente (e hoje possivelmente de formas mais explícitas do que antes). Elas são também, renovadamente, reguladas, condenadas ou negadas (LOURO, 2001, p. 9).

O investimento da fabricante de Barbie, a Mattel, no "ser menino" pode ser visualizado também em um site azul com jogos dos carrinhos Hot Wheels. Nele, o menino é estimulado a conhecer diversos jogos de corrida, destruição, ataques aéreos, skate e batidas. O site é ilustrado por pneus em chamas, raios, monstros, caveiras, veículos em alta velocidade e dinossauros. Ao clicar em uma das opções de diversão, ouve-se o ruído de um carro acelerando. As instruções de cada jogo são acompanhadas de imperativos como "Acabe!", "Destrua!", "Acelere!", "Detone!", "Melhore o desempenho"... E, é claro, "Colecione!". Outros adjetivos são comumente usados, como "irado" e "radical". Já no site de Barbie, o cenário é o quarto cor-de-rosa da boneca e suas parafernálias, alguns dos imperativos são: "Decore com Barbie", "Vá às compras com Barbie" e "Venha ao reino encantado".

Ambos os sites apresentam produtos à venda e a maioria deles pode ser encontrado em versões "masculinas e femininas". Assim, no site de Barbie, a bicicleta fabricada pela Caloi tem a seguinte mensagem publicitária: "Se exercitar e passear será muito mais divertido, ainda mais com a Barbie pedalando junto com 
você! Ainda vem com uma mochilinha!”. Já no site dos meninos, a mensagem de venda da bicicleta feita pela mesma fabricante é: "Pilote esta super bike que vem com simulação de tanque de gasolina e guidão com som de acelerador".

O menino tem, portanto, uma bicicleta que lhe autoriza a "acabar, destruir e detonar" a mocinha adversária que passeia tranquila com sua mochilinha rosa no meio do caminho. Na seção de vestuário, a menina, se quiser comprar meias, tem como opção as "meias da Barbie para você ficar quentinha, confortável e super fashion! O kit ainda vem com um lindo porta-retrato magnético!”. Já os meninos usarão as meias Hot Wheels, que servem "para praticar esportes super radicais, aquecer e proteger seus pés". Os publicitários supõem serem os pés dos meninos mais ativos e que precisam de maior proteção contra o impacto de seus movimentos. Já os pés das meninas devem ficar quentinhos e confortáveis, debaixo das cobertas, ou serem exibidos para as amigas com a meia da moda Barbie.

Há ainda a seção de beleza, na qual meninas e meninos encontram produtos diferenciados para comprar: enquanto estes podem adquirir a escova de dente Hot Wheels e "acelerar sua escova para deixar seus dentes limpos em tempo recorde", as meninas usarão o perfume Barbie Pink, "um perfume delicioso com aroma de rosas!" 14 .

As crianças aprendem a enxergar com naturalidade os abismos que separam seus brinquedos nas gôndolas em faixas etárias e gêneros distintos. Meninas e meninos são vistos como segmentos de mercado e os brinquedos são fabricados e expostos nas lojas de modo que lhes fixe uma identidade. Enquadradas em um perfil de consumo, acredita-se que as crianças terão uma experiência agradável de compra ao deparar-se com um brinquedo personalizado para "suas necessidades sexuais e características etárias".

\section{O que ensina a "melhor amiga" da menina? Há sempre um filme novo para assistir e aprender...}

Os filmes Barbie ${ }^{15}$ reforçam a maneira "sensível" de como a menina deve ser instruída e promovem a boneca ao papel de atriz que vive histórias de prin-

\footnotetext{
${ }^{14}$ Transcrição da publicidade dos sites $<$ www.barbie.com.br $>\mathrm{e}<$ www.hotwheels.com.br $>$. Acesso em: 3/ 3/2008.

${ }^{15}$ Uma análise dos filmes Barbie mais detalhada foi apresentada na $30^{\mathrm{a}}$. Reunião Anual da ANPED, 2007 e também publicada com modificações na Revista Labrys n. 13, 2008. Disponível em: $<$ http://www.unb.br/ih/his/gefem/labrys13/perspectivas/fernanda1.htm>. Acesso em: 20/11/2008.
} 
cesas encantadas. Príncipes-heróis aparecem em todas as histórias e a cada uma, novo ícone do romantismo cruza o destino de Barbie para fazê-la sonhar com o amor eterno e verdadeiro que conduzirá ao casamento. Assim, a celebração desse amor, que se acredita ser inato à mulher e não socialmente construído, dá-se a partir de um ritual composto por cenários luxuosos, roupas e penteados de gala, mostrando o triunfo do casal e a felicidade dos personagens que fizeram o bem. No musical Barbie - A princesa e a plebéia, a boneca canta várias canções que ensinam como a menina precisa comportar-se para ser uma verdadeira princesa. Tomamos aqui alguns trechos da letra dessa música bastante significativos:

[...] Uma princesa nunca esquece de sorrir

Pés delicados ao dançar

O protocolo, respeitar!

Goste ou não a solução é dizer sim

[...] Caminhando com cuidado

Um sorriso delicado

$\mathrm{O}$ que sente nunca demonstrar!

Voar...

[...] Uma princesa sabe como se portar

Uma princesa nunca pode descansar

Ser paciente e sorrir

[...] Sua postura, sim

A postura, por favor

Um golinho assim

Tenha sempre bom humor

Esperar a hora certa pra dizer

Uma princesa não precisa cozinhar

Uma princesa sabe como encantar!

Ao final do filme, a criança tem a opção de selecionar as músicas que fizeram parte da história e memorizá-las cantando com Barbie, em forma de karaokê. A boneca incentiva a menina dizendo: "Eu gosto dessa música porque ela nos ensina a ter bons modos de maneira bastante divertida" e "Eu sei que você tem uma voz linda!". A publicidade da boneca insiste na ideia de que ter bons modos e sorrir delicadamente é um requisito indispensável para que a mulher seja considerada no meio social. De acordo com Schiebinger (2001, p. 163), 
Das mulheres, que se espera que exibam polidez na fala e nas maneiras, se exige, mais do que dos homens, que sorriam. Quando ouvindo, uma mulher deve assentir com a cabeça e sorrir para expressar atenção. Se uma mulher não sorri, ela pode ser percebida como estando zangada. As mulheres estão muito representadas em profissões que requerem sorriso, tais como cuidar de crianças pequenas, enfermagem, ensino, servindo como aeromoças ou secretárias.

Esse tipo de ideologia veicula também a ideia de que a menina deve fazer brotar de seu coração os sentimentos de ternura, amizade, esperança e docilidade. Rael (2003, p. 169), ao analisar os desenhos infantis produzidos pela Walt Disney, aponta que em muitas histórias o feminino e a afetividade se conectam, naturalizando a menina como sensível, doce e paciente:

[...] as representações dos desenhos procuram mostrar que o ideal de feminilidade está estritamente vinculado ao coração. Justifica-se, assim, o discurso que procura enfatizar que as mulheres são mais dóceis, mais emotivas, mas fracas e dependentes, devido às características físicas que possuem.

O discurso também é reproduzido na sinopse do filme: "Nesta mágica performance musical, duas belas e corajosas garotas ousam seguir seus sonhos e descobrir que o destino está escrito em um lugar muito especial: seu coração!". Com grande sedução, a loura boneca apresenta uma maneira de ser mulher e mostra à menina os sentimentos que devem ser cultivados no coração para que todos os sonhos de sucesso, prestígio, beleza e consumo se realizem para sempre.

Machado (2007), ao analisar o papel das heroínas no cinema de animação, conclui que

Ao representar os gêneros, percebo que a mídia não é apenas um espelho fiel ou distorcido da realidade. Ela é instituidora de realidades, na medida em que estabelece valores e normas, participando ativamente da construção do sistema de sexo-gênero: flerta com os feminismos, valoriza a verdadeira mulher, promove uma visão oposta e complementar acerca dos gêneros. O intento é o prazer do público: novos valores, novas representações, exposição de conflitos, nada disso pode superar o lúdico, a fantasia, a satisfação. O resultado é, de fato, uma negociação aprazível, 
já que evita apontar para conflitos insolúveis e/ou desagradáveis. Ao contrário, o final consagra o amor, a união, a bondade e a beleza, temperados com picardia e ironia.

Inúmeras outras animações são protagonizadas pela boneca, e a publicidade de Barbie esforça-se para capturar a menina e encaminhá-la a seu mundo fictício. Nele, a garota é convidada a penetrar e a desfrutar de cenários oníricos onde nuvens, estrelas, palácios e a cor rosa possam mostrar, junto à amiga Barbie, tudo o que a menina precisa desejar para si. Terminado o sonho, ao sair do universo fantástico criado para dar vida à boneca, a telespectadora pode encontrar em qualquer loja de brinquedos os mais variados caprichos que fizeram parte do cenário da musa.

Barbie está imersa num mundo de imagens e sons, e é sempre bom lembrar que as imagens não são nem ingênuas nem neutras. Imagens são vozes que falam de um tempo, de um tema, de um desejo... Como uma boneca, matéria, brinquedo, torna-se um ícone imagético e assume visualmente emoções humanas? Como suas imagens, em veloz movimento, produzem uma verdade?

As imagens de Barbie são lançadas em filmes de acordo com um projeto artístico, cultural e de mercado. Inúmeras tecnologias de um processo industrial produzem o "real" a ser consumido. As imagens que vemos em movimento nos educam, provocam redes de emoções e realidade: são imagens vistas e não lidas ou escutadas. Almeida (2004) sublinha que as pessoas são educadas cada vez mais pelo que veem no cinema e na televisão, e não por um texto escrito. Nós somos os consumidores dessas imagens e não os produtores. Enquanto estivermos despreparados para lê-las, o cinema as movimenta infinitamente e o mercado produz uma opinião pública com efeito de verdade.

O espectador de cinema ou de televisão passeia ingênuo e desarmado, buscando seu prazer em meio a um mercado que não é nem ingênuo, nem desarmado. E é bom que se diga desde logo que o cinema e a televisão não são meios democráticos como a sua intensa difusão popular parece mostrar (ALMEIDA, 2004, p. 23).

Enquanto a menina ri, diverte-se, canta, chora, aprova ou desaprova os desenhos Barbie, ela satisfaz-se desarmada nesse mercado que não é inocente. Seduzida para o consumo, a criança pode desejar comprar e assistir filmes inúmeras vezes, mas dificilmente poderá produzi-los. As imagens movimentam-se 
para fazê-la perceber e querer. Nesse mercado, ao consumidor é permitido ter criatividade e não imaginação. A imaginação é um deslocamento fora do mundo cotidiano e exige lentidão: Os filmes são produzidos em massa para um "grande olho-ouvido", para uma opinião pública, uma estatística (ALMEIDA, 2004, p. 26).

Barbie aparece em narrações cronológicas que reservam um "sentido" a ser mostrado no final. Sendo este sempre feliz, as vozes vencedoras anunciam: faça dessa maneira para terminar assim! Os filmes estão repletos de figuras modelares que não existem: o máximo do bem e o máximo do mal; ninguém consegue ser igual a esses modelos e, mesmo que saibamos que não existe o "final feliz", as imagens benevolentes aparecem para recompensar o conformismo social, dizendo: "Não se preocupe, basta fazer como eu e tudo ficará bem...".

As imagens e os mandamentos da boneca disseminados pela sua forte publicidade também são obedecidos e respeitados por um fiel público de adultos colecionadores. Mais de 20.000 leitores norte-americanos compram a revista bimestral Barbie Bazaar, uma publicação com fotos antigas da boneca e de seus acessórios. Para Lord (2004, p. 5), esse não é um número insignificante de discípulos, já que o cristianismo, por exemplo, iniciou apenas com 11. Os colecionadores, homens e mulheres na maioria com idade entre 40 e 50 anos, compartilham sua devoção por Barbie em convenções mundiais realizadas há quase 30 anos.

Fascínio, prestígio e oblação... Uma boneca que já usou mais de um bilhão de pares de sapatos e alcançou a medida de mais de sete voltas ao mundo pelos exemplares vendidos não pode proteger-se por muito tempo atrás das cândidas embalagens que a abrigam nas lojas e tampouco se passar por ingênua nas mãos da menina. Algo a eleva da condição de boneca e deixa-nos a dúvida: mas $o$ $q u e ̂$ - e até mesmo quem - é Barbie afinal de contas?

Para recontar a história do aparecimento de Barbie em nosso país é preciso reunir cacos mergulhados no silêncio, memórias de um quadro que se fragmentou ruidosamente. Neste trabalho, foram encontrados alguns pedaços que não se alinham aos outros, deixam ainda pequenas fissuras para que nossa imaginação refaça a imagem da boneca norte-americana nos primeiros anos de seu "descobrimento" do Brasil.

No início dos anos de 1980, numa época em que a infância de muitas meninas fora marcada por referências de feminilidade apresentadas por Xuxa, apresentadora de programas infantis de aparência semelhante à da boneca norte-americana, Barbie iniciava sua carreira no país também como uma "estrela". As narrativas da boneca alimentavam o sonho de um estilo de vida projetado para o consumo, ensinando às meninas que o sucesso está no corpo magro e branco. Sob a camuflagem da fantasia e do ambiente festivo, os cenários em 
que Barbie é inserida evocam o consumo infantil pela imitação de suas atitudes e de seus trajes. Corpos de Xuxa e Barbie configuram severas lições sobre as expectativas sociais em relação à aparência feminina. O universo de ambas, constituído pela constante troca de figurino, estimula as meninas a desejarem seus modelos supostamente ingênuos.

Barbie foi pensada para ser a primeira boneca a ter uma coleção de trajes que pudessem ser adquiridos separadamente, fazendo da troca de roupas a essência da brincadeira. A menina que brinca com Barbie sonha ser como ela e é instigada a renovar e colecionar roupas e acessórios, pois sem uma variedade deles se acredita não ser possível simular personalidades e funções diferentes para a boneca. A publicidade seduz a menina oferecendo a ela a suposta liberdade de escolher o que e quem sua Barbie vai representar e por quanto tempo quiser. Inúmeras coleções de roupas dão à boneca qualquer disfarce que ela precisar para fingir ser Barbie: a Fada do Arco-Íris, Barbie, a Princesa Bailarina e tantas outras simulações.

Ser a Barbie... Num fenômeno de mimetismo e atração magnética, crianças configuram em si as características e a aparência de uma boneca fabricada com ingredientes nocivos. Elas aprendem que é preciso adquirir o corpo rígido, plástico, tóxico de Barbie: abrigar em si o silicone, o botox e, se preciso, até o formol nos cabelos para alisá-los. Ao corpo cabe o preenchimento com os produtos químicos e letais que substituem qualquer aparência indesejada, qualquer marca do tempo. Drogas populares (Prozac, Lexotan, Ritalina) são usadas sem medida para efeitos imediatos no comportamento, e substâncias químicas são vendidas a escolher para quem deseja adquirir desempenho atlético. A própria morte torna-se obsoleta e a carne perturba. Eis os venenos!

$\mathrm{Se}$, no início da carreira, Barbie fora modelada com o perfil de pessoas e atrizes reais: Jacqueline Kennedy, Madonna e Whitney Houston, por exemplo - nos anos de 1980 as mulheres reais é que estavam se modelando baseadas em Barbie. O ideal de beleza materializou-se em boneca: embalada e mostrada nas lojas, seu suporte de sustentação é a mão da menina, que com ela brinca e sonha ser estrela. A boneca foi transformada em pedaço de vidro refletor, um espelho no qual são revelados os vícios de quem a contempla e, ao mesmo tempo, estampadas as virtudes a serem conquistadas pela mulher. Barbie foi feita para ser o espelho inquebrável que reflete a "melhor" decoração possível para corpos humanos, tidos como frágeis e vulgares, os corpos femininos ${ }^{16}$.

A personificação de Barbie e sua transformação em um ícone de mulher sugere que as pessoas reais são feitas de carne de má qualidade, por isso são

${ }^{16}$ Sobre a educação do corpo, ver as pesquisas de Sant'anna (1995) e Soares (1998; 2001). 
carentes de melhorias e precisam que seus contornos se convertam em beleza plástica. Enquanto as mulheres pagam e arriscam suas vidas para se tornarem bonecas, Barbie esforça-se para ser viva, "humanamente possível", uma modelo insólita de mulher. O'Sickey (2002, p. 47) entende a transformação do produto em mulher e da mulher em produto como "uma construção marcada pelo investimento, mensurável em capital, no sentido de que a base material para a auto-alienação da mulher é a ansiedade de não estar à altura dos padrões de beleza feminina gerados pela cultura mercantilista e pelo capitalismo consumista".

Barbie é uma imagem de "virtudes" e seu espelho reflete a fundo os vícios de quem a contempla. Ao mesmo tempo em que afirma: veja como sou linda, simpática e célebre, também diz: olhe para você, garotinha e tente fazer como eu: arrume-se, sorria e mostre-me quem é a mulher que você quer ser...

\section{REFERÊNCIAS}

ALMEIDA, M. J. de. Imagens e sons: a nova cultura oral. São Paulo: Cortez, 2004.

FELIPE, J.; GUIZZO, B. S. Erotização dos corpos infantis na sociedade de consumo. Pro-Posições, Campinas, v. 14, n. 3, p. 119-130, set.-dez. 2003.

GÓMEZ, Z. P. Las huellas de la vida. Intervenciones estéticas y modelado del yo. Pro-Posições, Campinas, v. 14, n. 2 (41), p. 91-102, maio/ago. 2003.

KLEIN, N. Sem $\log o-$ A tirania das marcas em um planeta vendido. São Paulo: Record, 2006.

LORD, M. G. Forever Barbie - The unauthorized biography of a real doll. New York: Walker \& Company, 2004.

LOURO, G. L. Pedagogias da sexualidade. In: . (Org.). O corpo educado - pedagogias da sexualidade. Belo Horizonte: Autêntica, 2001. p. 7-34.

MACHADO, L. Heroínas de celulose: uma abordagem interdisciplinar do cinema de animação. Labrys, Estudos Feministas, n. 12, jul.-dez. 2007. Disponível em: <http:// www.unb.br/ih/his/gefem/labrys12/livre/liliane.htm>. Acesso em: 25/5/2008.

MÉDOLA, M. Espelho, espelho meu... Metrópole, Campinas, p. 8, 18/03/2007.

O'SICKEY, I. M. A Revista Barbie e a utilização estética do corpo das meninas. In: BENSTOCK, S.; FERRIS, S. (Orgs.). Por dentro da moda. Rio de Janeiro: Rocco, 2002. 
RAEL, C. C. Gênero e sexualidade nos desenhos da Disney. In: LOURO, G. et al. (Org.). Corpo, gênero e sexualidade: um debate contemporâneo na educação. Petrópolis: Vozes, 2003.

SABAT, R. Gênero e sexualidade para consumo. In: LOURO, G. L.; NECKEL, J. F.; GOELLNER, S. V. (Orgs.). Corpo, gênero e sexualidade: um debate contemporâneo na educação. Petrópolis: Vozes, 2003.

SANT’ANNA, D. B. de (Org.). Políticas do corpo. São Paulo: Estação Liberdade, 1995.

SCHIEBINGER, L. O feminismo mudou a ciência? Bauru: EDUSC, 2001.

SCHWARTZ, J. et al. Mulheres na informática: quais foram as pioneiras? Cadernos Pagu, n. 27, p. 255-278, jul./dez. 2006.

SOARES, C. L. Imagens da educação no corpo. Campinas: Autores Associados, 1998. . Corpo e história. Campinas: Autores Associados, 2001.

\section{Filmes}

BARBIE: A PRINCESA E A PLEBEIA. Direção de William Lau. Universal Home Video, 2004. DVD.

BARBIE FAIRYTOPIA. Direção de Walter Martishius. Universal Pictures, 2004. DVD.

BARBIE-QUEBRA-NOZES. Direção de Owen Hurley. Universal Pictures, 2002. DVD.

Texto recebido em 28 de agosto de 2009.

Texto aprovado em 23 de fevereiro de 2010. 